\title{
Modular Approach to Ultra-fast Charging Stations
}

\author{
Carola Leone $^{1}\left[\right.$ (D) Michela Longo $^{1}$
}

Received: 5 November 2020 / Revised: 2 March 2021 / Accepted: 12 April 2021 / Published online: 29 April 2021

(c) The Author(s) 2021

\begin{abstract}
Road transport electrification is essential for meeting the European Union's goals of decarbonization and climate change. In this context, an Ultra-Fast Charging (UFC) system is deemed necessary to facilitate the massive penetration of Electric Vehicles (EVs) on the market; particularly as medium-long distance travels are concerned. Anyway, an ultra-fast charging infrastructure represents the most critical point as regards hardware technology, grid-related issues, and financial sustainability. Thus far, this paper presents an impact analysis of a fast-charging station on the grid in terms of power consumption, obtained by the Monte Carlo simulation. Simulation results show that it is not economical convenient size the assumed ultrafast charging station for the maximum possible power also considering its high impact on the grid. In view of the results obtained from the impact analysis, the last part of the paper focuses on finding a method to reduce the power installed for the DC/DC stage while keeping the possibility for the electric vehicle to charge at their maximum power. To achieve this goal a modular approach is proposed. Finally, two different modular architectures are presented and compared. In both the solutions, the probability of having EVs charging at limited power is less than 5\%.
\end{abstract}

Keywords Electric vehicles · Charging station · Ultra-fast charging $\cdot$ Modular infrastructure $\cdot$ Transportation electrification

\begin{tabular}{ll}
\multicolumn{2}{l}{ Abbreviations } \\
EV & Electric Vehicle \\
PEV & Plug-in Electric Vehicle \\
BEV & Battery Electric Vehicle \\
UFC & Ultra-Fast Charging \\
BMS & Battery Management System \\
SoC & State-of-Charge \\
Pc & Charging Power \\
Ebat & Capacity of the Battery \\
Crate & Charging Rate \\
$Q_{\mathrm{C}}$ & Battery available capacity \\
$Q_{n}$ & Battery rated capacity \\
FdF & Frequency distribution Function \\
pdf & Probability density function \\
b & Weibull shape parameter \\
a & Weibull scale parameter \\
$\mu$ & Average value \\
$\sigma$ & Standard deviation
\end{tabular}

Carola Leone

carola.leone@polimi.it

Michela Longo

michela.longo@polimi.it

1 Department of Energy, Politecnico Di Milano, Milan, Italy

\section{Introduction}

Road transport electrification is inevitable for meeting the European Union (EU) aims of decarbonization and climate change, since this sector is responsible for about $20 \%$ of $\mathrm{CO} 2$ emissions within the EU [1]. Electric Vehicles (EVs) running only on electricity have zero tailpipe emissions, but there are upstream emissions coming from manufacturing cycle and from electricity generation [2]. Concerning the latter, it is clear that the use of relatively low-polluting energy sources for electricity generation will lead to a stronger well-to-wheel emissions advantage of EVs over similar conventional vehicles running on gasoline or diesel. Instead, in regions that depend heavily on coal for electricity generation, EVs may not demonstrate a strong Well-toWheel (WTW) emissions benefit, as shown in [3], where the region with the highest carbon intensity is Germany. For this reason, the introduction of EVs on the market and the installation of Renewable Energy Sources (RESs) are rising hand in hand. The degree of electrification together with the traffic conditions are two other important factors to consider in the WTW analysis [3, 4]. Eventually, from an analysis of independent life cycle assessment (LCA) studies [4-7], it is possible to conclude that a BEV over its lifetime 
produces $50 \%$ less $\mathrm{CO} 2$ emissions than a standard EU car today (Fig. 1).

Electric cars are expected to account for $16 \%$ of the global car fleet in 2030, rising to 51\% in 2040 and to $69 \%$ in 2050 [8]. On one hand this electrification process will lead to a significant drop of the average GHG emissions; however, on the other hand, it will require the integration of vehicles into a reliable and affordable as well as easy-of-use infrastructure for the supply of energy [9].

Nowadays, slow charging is the most popular method of charging EVs, in fact is preferred by many car owners when they intend to stay for a long period at the destination such as at home overnight or at the job location during the working day $[10,11]$. Slow charging points typically have power ratings that vary from $3 \mathrm{~kW}$ (1-phase) up to $22 \mathrm{~kW}(3$-phase) and hence required charging times which last usually between $3 \mathrm{~h}$ up to $11 \mathrm{~h}$ [12]. Nevertheless, slow charging methods can not satisfy the entire needs of the electric mobility field. Particularly, as medium and long-distance trips are concerned, an Ultra-Fast Charging (UFC) system is necessary for more widespread electric vehicle adoption [13]. In fact, the availability of a fast-charging infrastructure has demonstrated to be a crucial element that strongly and positively influences the driver's behavior in terms of average distance traveled, reduction of range anxiety, and general higher confidence with EVs [14].

Nevertheless, such a charging system has to face a number of serious challenges. First of all, it requires high initial investment costs $[15,16]$, since its installation involves upgrades in the power infrastructure such as the introduction of new transmission and distribution lines. Although the cost of fast charging equipment is about 10 times higher than that of conventional chargers, its return on investment is, in many cases, faster; since it allows to serve more vehicles a day. Another key factor in the relatively poor presence of UFC systems is its impact on the voltage stability of the distribution network [17-19]. This system can cause, in fact, voltage fluctuations and flicker, which, however, can be almost completely mitigated with the use of both smart

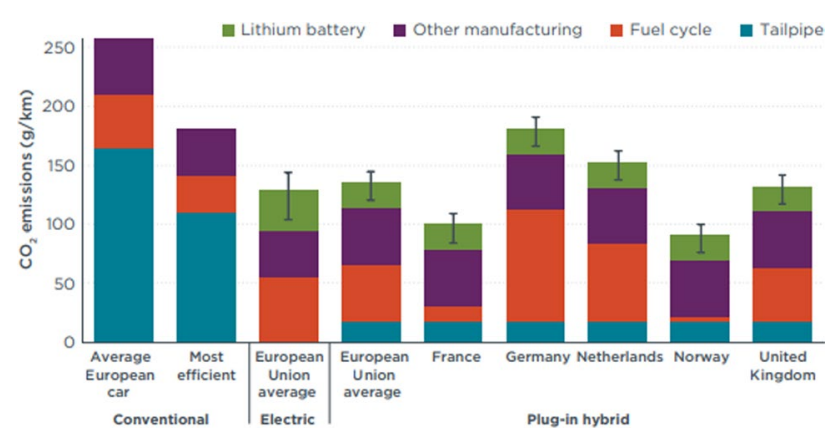

Fig. 1 WTW GHG emissions for different electricity production and degrees of electrification [3] charging algorithms and on-site distributed energy resources [18]. Moreover, the charging capacity of the different electric vehicles up to now on the market varies in a wide range, making in this way, difficult the choice of the optimal size for such a charging system: if the UFC station is sized for the maximum charging power allowable by the EVs, then it will operate for most of the time at a lower rating leading in this way to poor efficiency values.

Thus far, this paper aims to quantify the effective impact of an ultra-fast charging station on the grid. Factors such as the differences among electric vehicle models, initial SOC, and different arriving times to the charging point are considered in the Monte Carlo simulation. Due to the low load factors, high initial costs, and low flexibility the concept and the advantages of a modular and reconfigurable charging station are introduced. This adaptability could result in a particularly important feature today as innovations and new materials continue to be introduced into EV battery and power-stage components $[19,20]$; not to mention the differences that already exist between different typologies and models of EVs. Finally, two modular architectures are proposed and preliminary compared in this paper.

\section{State of the Art}

In this paragraph, the current state of the art of ultra-fast charging station for EVs is described.

Due to large power requirement, a UFC station needs a connection to the medium voltage MV network [21], indeed in [22] Sun et al. present that a DC fast charger connected to the MV grid can lower about $75 \%$ of the losses with respect to a charger of the same power connected to the $480 \mathrm{~V}$ grid. The grid medium voltage is then stepped down by an isolating Line Frequency (LF) transformer whose secondary will be converted in DC. The typology of transformer depends on the AC-DC converter chosen [23]. However, in recent years a lot of research is focusing on substituting the linefrequency transformer with a Solid-State Transformer (SST) [24-28]. Such approach will enable the direct connection of the station to the MV line by providing step-down, rectification and isolation functions in a single unit. The adoption of such technology will lead to a lighter, cheaper and more efficient system. In fact, compared with traditional transformer, the SST presents some benefits such as the exploitation of a high-frequency transformer, a better fault current limiting capability, a lower cost and higher flexibility. Despite its advantages, some serious issues, in particular, in terms of reliability and protection devices could potentially limit the applicability of SSTs [26, 27].

Before establishing the AC-DC converter, the first decision to be made in the design of a UFC station is whether to follow a common $\mathrm{AC}$ or a common DC bus approach 
as shown in Fig. 2. Nevertheless, this holds only in case of line frequency transformer, in fact if the SST is chosen as connection to the grid, a common DC bus configuration is the only possible solution, since the mentioned technology covers the functionality of LF transformer and AC/DC conversion.

In an $\mathrm{AC}$ bus configuration, the secondary winding of the LF transformer is used to individually supply the charging columns. Therefore, with such an approach all the charging units have their own rectification stages connected to the AC bus. In [29] a EVs fast charging station integrated with an energy storage system is implemented following the AC-bus scheme. The main reason behind the authors' choice is that the AC system is a well-integrated technology for which there are well-developed standards and technologies on the market. However, the DC bus approach is becoming the preferred solution because of its several advantages over the AC bus approach [30, 31]. First of all, a DC bus-based system allows a reduction of the number of components, since a common AC/DC converter is used. With fewer conversion stages an improvement of both the efficiency and the cost of the overall system is possible. For instance, in [32] authors estimate that in DC bus systems the conversion losses can

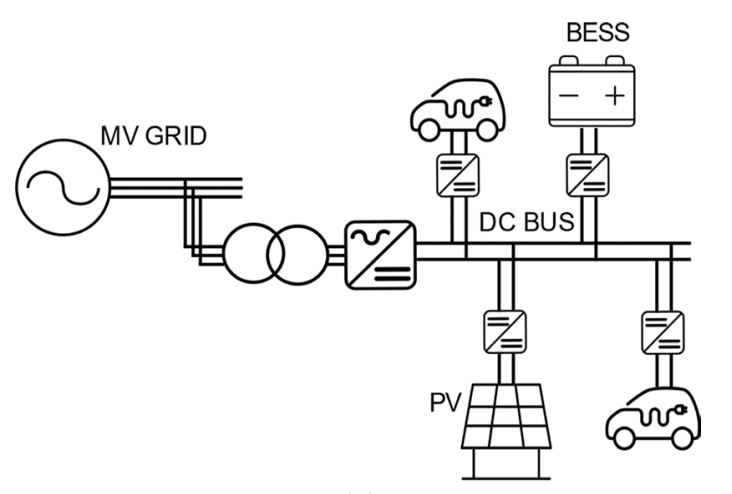

(a)

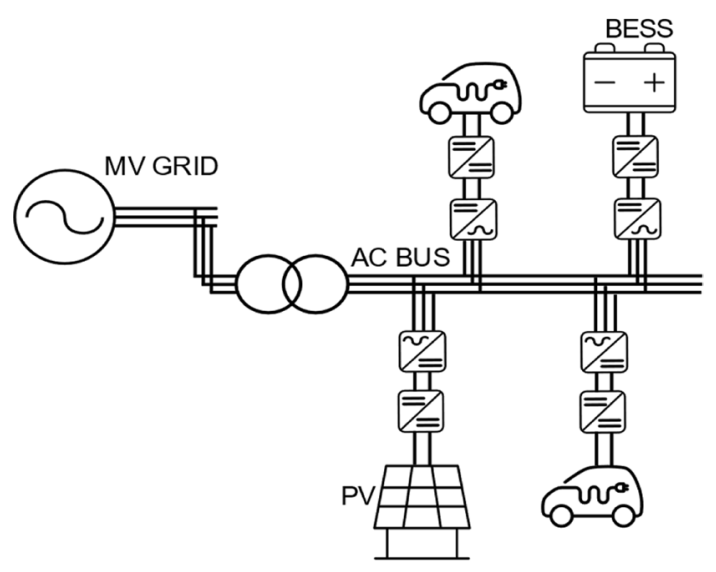

(b)

Fig. 2 Charging station architecture: $\mathbf{a}$ DC bus $\mathbf{b}$ AC bus be decreased from about $32 \%$ to less than $10 \%$ with respect to an $\mathrm{AC}$ bus architecture. Moreover, the absence of reactive power allows an easier control, [16,33]. With a DC bus architecture is also easier to integrate Renewable Energy Sources (RESs) and Energy Storage Systems (ESSs) that can be used to mitigate the negative impact of the UFCS on the distribution MV grid [30]. This fact must not be underestimated, as a matter of fact in [34] authors shown that fast charging stations can increase the peak demand by about $9 \%$, hence causing in addition to the voltage flickers also the drop of the bus voltages bellow the admissible limit (-0.95 $\mathrm{pu}$. The advantages of inserting ESSs and RESs is highlighted in different works. In [35], the authors proposed an energy management system for a fast-charging station (FCS) composed of two fast chargers of $48 \mathrm{~kW}$, a battery energy storage system consisting in a $23.9 \mathrm{kWh}$ Li-ion battery, and a PV system with a peak power of $119 \mathrm{kWp}$. The results of this work show that with the designed configuration the FCS mainly operates in stand-alone mode, and hence almost completely canceling the impact on the grid. On the other hand, according to [26], the major issues of a common DC bus architecture are related to the protection and metering devices.

Since in a UFC station electric vehicles seek considerable level of energy in very short time intervals, the implementation of a bidirectional power flow is counterproductive [36]. In this context, if only unidirectional current flow is requested a three-level three-phase Vienna rectifier represents one of the most suitable candidates to perform the common AC/DC stage [16, 23] in a DC bus configuration. This topology, shown in Fig. 3, with a lower number of active switching devices compared to the other three-level converters, features a highly sinusoidal input current, low voltage stress in the devices, a high-power factor operation and a high reliability in case of malfunctioning, in fact, it is well protected in case of short circuit and it can even operate

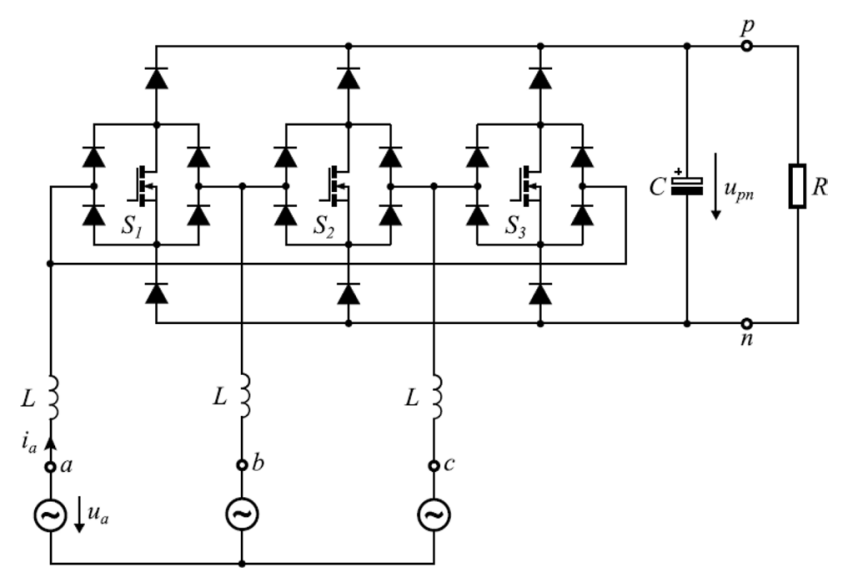

Fig. 3 Vienna rectifier 


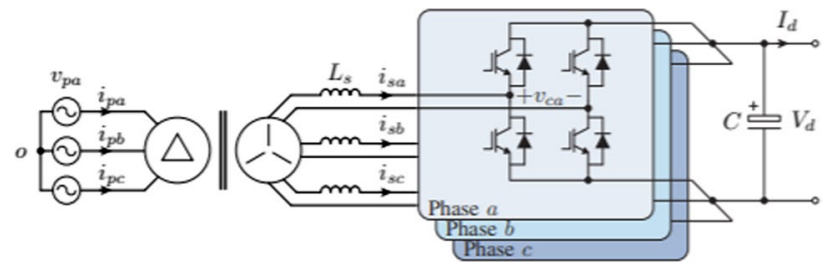

Fig. 4 Power circuit of the HB converter in [38]

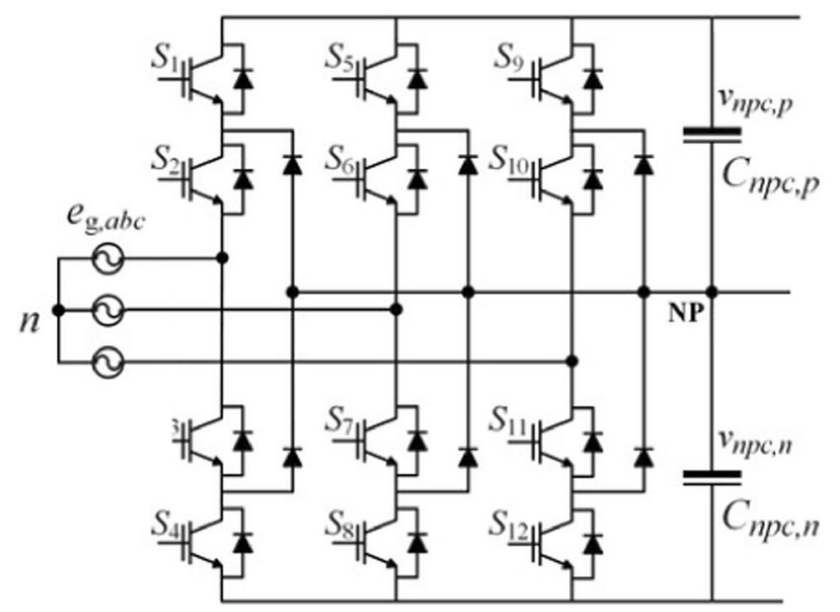

Fig. 5 Three-level three-phase NPC converter

with the loss of one input phase [37]. Its major limitations are the need for dc-link capacitor voltage balancing and the limited reactive power control.

Another rectification stage becoming popular in fast charging station is the multilevel ac/dc converter [38, 39]. In particular the typologies of multilevel converters which seems to be more promising in the field of charging station for $\mathrm{EC}$ are the cascade H-bridge (CHB) and the neutral point clamped (NPC). For instance, in [38], Rivera et al. propose a 3-level h-bridge (HB) converter rated as $690 \mathrm{~V}$ and $1.2 \mathrm{MW}$ as the grid interface in a dc charging station; its configuration is shown in Fig. 4. The main points in favor of the proposal are the low THD values and the lack of unbalances issues both in the ac and dc sides; moreover, the converter achieves an output three-level waveform without any balancing requirements and without the use of clamping diodes, which instead are necessary in the (NPC) converter proposed as grid interface in [42]. The use of the NPC converter, depicted in Fig. 5, automatically leads to a bipolar DC-bus architecture, which offers as main advantages high power capacity and better current performances, however it produces power imbalances between the positive and negative output bars [41]. In [40] a CHB converter is again proposed as ac/dc stage in a UFC station.

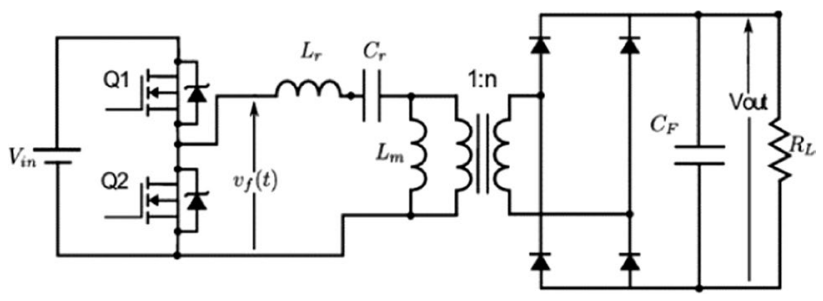

Fig. 6 LLC resonant converter

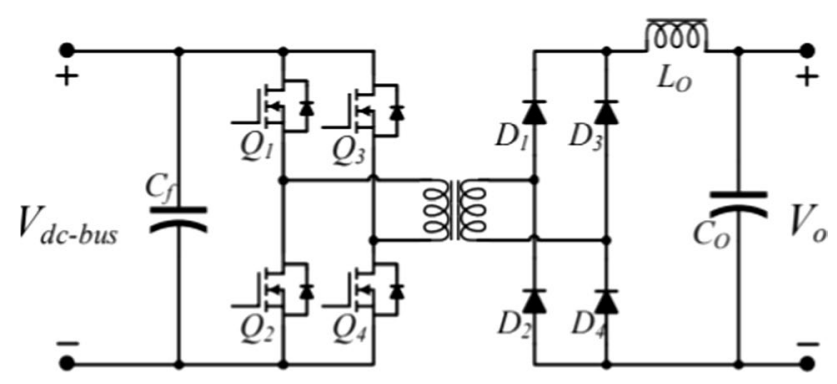

Fig. 7 Power circuit of a PSFB converter

After the AC/DC stage, the DC/DC converter provides an interface to the EV battery. A requirement expressly demanded in IEC 61,851-23 [40] for multiport charging stations is the galvanic insulation between each individual output. The reason for this requirement is the need to constantly monitor the insulation between the DC active parts (positive and negative pole) and the protective conductor or exposed conductive parts of the vehicle (which can be touched) in order to quickly detect a fault and disconnect the power supply. This aim can be achieved by using an isolated DC/DC converter.

Recently an isolated unidirectional DC/DC converter which is gaining ever more attention is the LLC resonant converter, whose scheme is reported in Fig. 6. The LLC converter presents many advantages over other resonant topologies [42, 43], such as: the ability to operate at ZeroVoltage Switching (ZVS) or Zero-Current Switching (ZCS), a wide output voltage regulation, and very high efficiency. Moreover, its output filter consists only of a capacitor and not of an inductor and capacitor (LC) filter [16]. A more comprehensive description of this type of converter is provided in [24] and [44].

In [45] authors design a $50 \mathrm{~kW}$ phase-shift full-bridge (PSFB) converter used EV battery interface for fast charging application. This type of isolated dc/dc converter, shown in Fig. 7 , is very common in high-power applications, this is due to its most desirable features such as high efficiency at high switching frequency attain through zero voltage switching, its simple design, and easy control method. 
A more complete review of the isolated dc/dc converters suitable for fast charging stations can be found in [46].

All the reference papers cited in this section highlight the different studied aspects of fast charging stations. As can be seen, most of the research focuses on the following topics: FCSs connection to the grid, their internal operation and design, their impact on the grid, the importance of an integration with RESs and ESSs, and the different EMSs that can be used. However, few studies focused on the sizing problem of a fast-charging station, as a matter of fact the power rate of the charger in all the reference papers is chosen a priori, without performing any investigation. As the name suggest, a UFCS aim to charge the EVs batteries as fast as possible. Therefore, the first aim of this work is to compute the maximum power absorbed by a UFC station composed of 10 charging ports, considering different aspects such as the different characteristics of today existing electric cars and their stochastic behavior.

\section{Impact Analysis on the Distribution System by Monte Carlo Simulation}

Ultra-Fast Charging requires a big amount of energy within limited intervals of time resulting in a very high-power density. This feature may pose undesirable issues on the national electric grid such as feeders and transformers overloading problems [28, 47], voltage drops [28, 48], and harmonic resonance risk [48]. Therefore, there is a need to investigate and model the impact on the grid of such a charging system. In this paragraph, the theoretical peak demand for electricity of a UFC station is carried out. More precisely, the power absorbed by the entire station is computed without going into the power delivered by each single charging pole.

\subsection{Considered Key Factors}

In the case of UFC station, the infrastructure is shared among different types of vehicles, which, having different charging profiles, require diverse charging strategies. More and more often it is possible to hear about very high power charger, able to provide $350 \mathrm{~kW}$; nevertheless, as shown Fig. 8, only a few EVs nowadays allow a charging power higher than $100 \mathrm{~kW}$; in fact, the charging time does not depend only on the output power of the charger but it is determined by the vehicle charging capability, which in turn depends on multiple factors.

The characteristics of the battery which influence the charging process, considered in this analysis, are listed below.

1)Capacity of the battery $\left(E_{b a t}\right)$ : The larger is the battery capacity of the vehicle the higher can be the allowed charging power [50]; in fact, according to (1), for a given value of

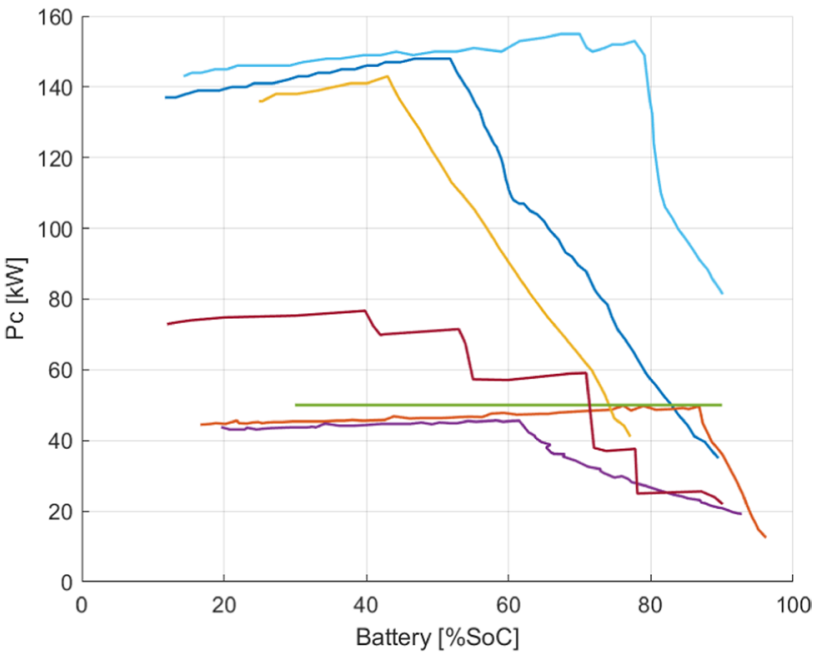

(a)

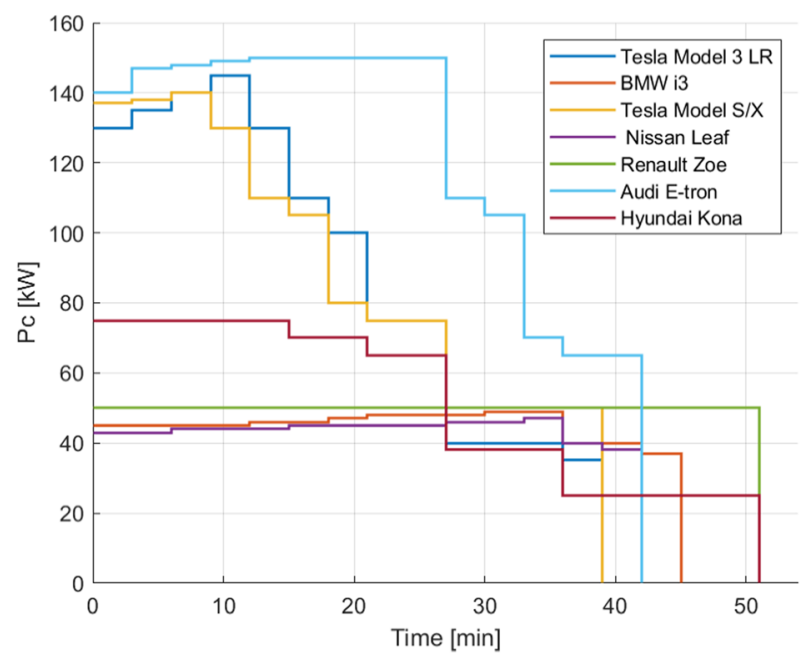

(b)

Fig. 8 Charging profiles of different EVs a as a function of \%SoC [49], $\mathbf{b}$ as a function of time

injected power as the capacity of the battery becomes larger, the $C_{\text {rate }}$ is reduced:

$C_{\text {rate }}=\frac{P_{c}}{E_{b a t}}$

where Pc indicates the charging power and Ebat the battery capacity. The $C_{\text {rate }}$ is the measure of the speed at which the battery is charged/discharged. High c-rates result in high aging rates. In fact, charging Li-ion batteries at a rate higher than $1 \mathrm{C}$ causes uneven heat generation inside the cell, mechanical pulverization of the electrode materials, and the occurrence of lithium plating reaction [50-53]. Therefore, the manufacturers have to deal with all these restrictions and set their limits through the Battery Management System (BMS), which will drive the charging process according to 
the proper charging profile and the allowed maximum charging rate of that specific vehicle [54].

2) State-of-Charge ( $\mathrm{SoC})$ : The $\mathrm{SoC}$ of a cell, expressed in (2), is defined as the percentage of currently available capacity $\left(Q_{c}\right)$ to its rated capacity $\left(Q_{n}\right)$ [55], and its value ranges between $0 \%$ up to $100 \%$.

$\% \operatorname{SoC}=\frac{Q_{c}}{Q_{n}} \cdot 100$

In general, the charging speed is strongly influenced by this factor. In fact, as the battery approaches a SoC around 60-70\%; the charging rate stars to drop quickly [56, 57]. Therefore, fast charging above $70-80 \%$ of the battery is not very useful.

3) Another external factor that can have a significant influence on charge speed is the temperature of the battery [58-60]. A battery works optimally if the temperature is not too high and not too low and in practice, this is usually between 15 and $35^{\circ}$ [61]. Nevertheless, such a factor is not considered in this study.

To consider in the analysis the above-mentioned features, which influence the charging process, a fleet of seven different electric vehicles, chosen among the top-selling models in 2018 and 2019, has been assumed in this study. The main characteristics of the chosen BEV models are reported in Table 1.

Figure 8a shows the charging profiles of the chosen models. Such trends are computed in optimal conditions, which means at ambient temperature and with new batteries. The charging profile $\mathrm{Pc}(\% \mathrm{SoC})$ of each vehicle has been discretized and then plot as a function of time $(\Delta t)$, according to the (3). Finally, Fig. $8 \mathrm{~b}$ reports the obtained discrete trends.

$\Delta t=\frac{P c \cdot \Delta \operatorname{SoC}(\%)}{E_{b a t}}$

At the end of each charging process, an interval lasting 3 min in which the charging power is nil has been introduced. This interval aims to reproduce and incorporate

Table 1 Features chosen BEVs

\begin{tabular}{llll}
\hline BEV model & $\begin{array}{l}\text { Declared } \\
\text { autonomy }(\mathrm{km})\end{array}$ & $\begin{array}{l}\text { Battery capac- } \\
\text { ity }(\mathrm{kWh})\end{array}$ & $\begin{array}{l}\text { Battery } \\
\text { technol- } \\
\text { ogy }\end{array}$ \\
\hline Tesla Model 3 LR & 530 & 75 & Li-ion \\
BMW i3 & 260 & 42.2 & Li-ion \\
Tesla Model S LR & 417 & 75 & Li-ion \\
Nissan Leaf & 305 & 40 & Li-ion \\
Renault Zoe & 395 & 52 & Li-ion \\
Audi E-tron & 400 & 95 & Li-ion \\
Hyundai Kona & 482 & 64 & Li-ion \\
\hline
\end{tabular}

the time needed: to pay the recharge, to disconnect the full charged vehicle, to connect, validate, and to start charging the new connected one. In almost all the trends, the charging profile stops when the vehicle battery reaches $90 \%$ of SoC.

The assumed station is composed of ten charging poles each one able to provide $175 \mathrm{~kW}$, for an overall maximum power of $1.75 \mathrm{MW}$. The theoretical maximum peak is then found assuming that ten vehicles, casually chosen among the seven models previously introduced, simultaneously occupy the ten poles. Once the vehicle is selected, its instantaneous charging power is randomly picked among the values in the corresponding charging profiles. This last passage aims to replicate the different arrival times to the station.

\subsection{Analysis and Discussion of Results}

In this way, 100.000 different scenarios are simulated. The number of bins is set according Sturge's rule in (4) and rounds up to 18 .

$k=1+3.322 \log _{10} N=17,67$

where $\mathrm{k}$ represents the number of bins and $\mathrm{N}$ is the number of observations.

Then, it is possible to define the relative frequency of each event as the ratio between the number of occurrences of that value and all the results of possible scenarios. The Frequency density Function (FdF) of the overall power simultaneously absorbed by 10 e-vehicles is reported in Fig. 9. The FdF is fitted with a normal distribution and with a Weibull one, whose expression are reported respectively in (5) and (6).

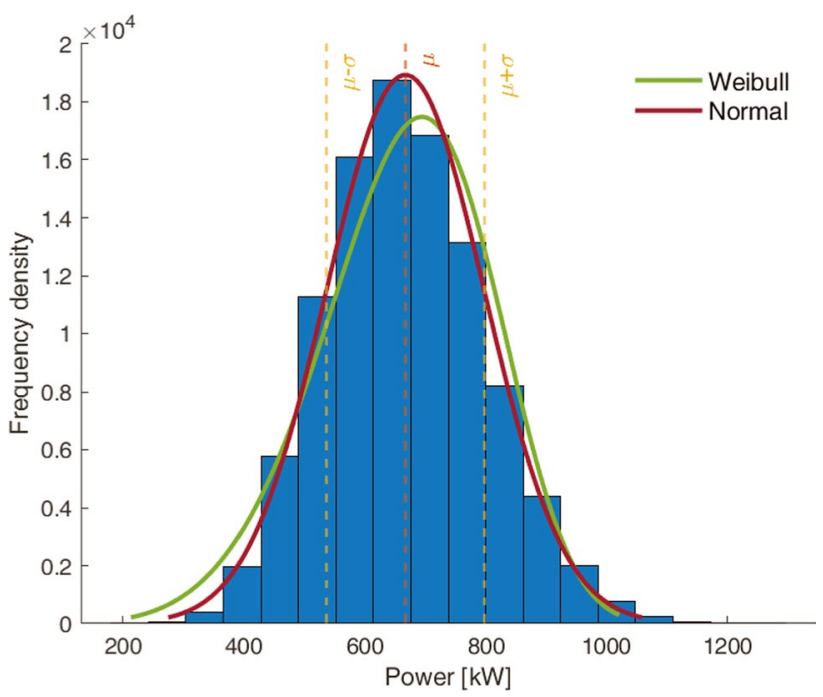

Fig. 9 Charging station power probability density function 
The Weibull probability density distribution is expressed as:

$$
\begin{aligned}
& f(x \mid a, b) \\
& =\frac{b}{a}\left(\frac{x}{a}\right)^{b-1} e^{-(x / a)^{b}}
\end{aligned}
$$

where $b$ is the shape parameter and a scale parameter. Particularly, in this study, these two parameters, which define the Weibull distribution, result respectively about 720 and 5.43 .

Instead the expression of the normal probability density function (pdf) is:

$$
\begin{aligned}
& f(x \mid \mu, \sigma) \\
& =\frac{1}{\sigma \sqrt{2 \pi}} e^{\frac{-(x-\mu)^{2}}{2 \sigma^{2}}}
\end{aligned}
$$

where $\mu$ is the mean and $\sigma$ the standard deviation. The mean of such distribution is computed thorough (7) and results about $667 \mathrm{~kW}$, as a consequence of the central limit theorem. Therefore, the results are strongly influenced by the models chosen to form the fleet, in other words this is a consequence of the influence of the battery capacity and SoC.

$\mu=\frac{\sum_{i=0}^{N} x_{i}}{N}$

where $x_{i}$ is the value of the power absorbed in the $\mathrm{i}$-th instant and $\mathrm{N}$ is the number of different instants/scenarios considered, in this case 100,000 .

The standard deviation is instead computed through (8) and results about $130 \mathrm{~kW}$.

$$
\sigma=\sqrt{\frac{\sum_{i=0}^{N}\left(x_{i}-\mu\right)^{2}}{N}}
$$

From such results, it is possible to conclude that by considering a UFC station able to provide a maximum power of $1 \mathrm{MW}$ is possible to satisfy more than $97.6 \%$ of probable scenarios. It is important make clear that the found peak demand does not represent any particular moment of the day, but it is a theoretical peak used to give a first size of an UFC station; moreover, the power conversion efficiency has not been considered.

\section{Modular and Flexible Design Proposal}

Given the results reported in the previous section, it may be concluded that to size the considered charging station, composed of 10 charging ports, for an overall power higher than $1 \mathrm{MW}$ it is not economical convenient, also considering its high impact on the grid. Therefore, now the attention moves to find a method to reduce the total power installed for the DC/DC converters while keeping the possibility for the EVs to charge at maximum power.

To achieve this objective a modular design is here proposed. According to such an approach, the DC/DC stage is composed of identical modules working in parallel configurations. These modules as shown in Fig. 15a are input parallel connected to a common DC bus bar, instead their outputs can be paralleled in different ways thanks to the presence of smart power switching devices. The different configurations of modules can be used to feed individual EV batteries, thus leading to the capability of simultaneously charging several electric vehicles at different power levels. Given the choice of the common DC bus, as previously mentioned, different types of RESs and ESSs can be easily integrated into the station design; however, in this work only the design of the chargers is addressed.

This modular and reconfigurable approach offers many advantages:

1.It simplifies the maintenance and replacement procedure [62]. The modules can be added and removed without compromising the functioning of the overall system.

2.It increases the flexibility for future expansions and future power requirements $[63,64]$. In fact, in the next years, more vehicles are expected to become capable of charging at high speeds [65] and this approach gives the possibility to easily scale up the power installed any wanted time with minimized processes [66]. This will allow the UFC stations of today to be compatible with tomorrow's requirements, minimizing and spreading the total cost of ownership and the initial investment over the years.

3.It allows much better use of the installed capacity [55]. As shown in Fig. 10, for a given value of installed power, the modular approach allows better management, enabling in fact to fully satisfy a higher number of simultaneous charging processes requiring different power values.

4.It enhances high efficiencies at low load. The vehicle characteristics and consequently their power charging requirements may differ considerably among the models and the different levels of SoC, for this reason, the converters of a conventional UFC station are sized for the maximum power, but they operate most of the time at a lower rating resulting in low light-load efficiencies. A modular architecture aims to improve this feature since it enables a more split use of the installed power. 


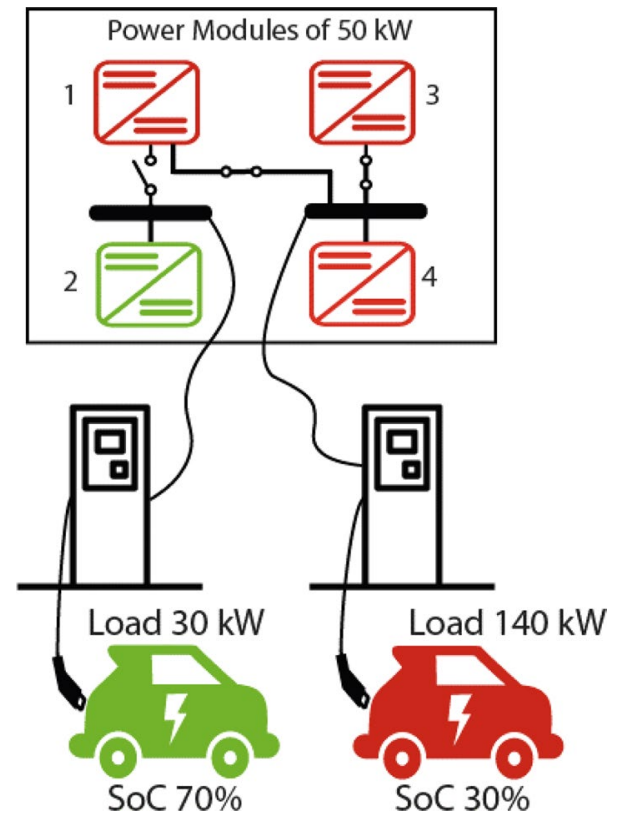

Fig. 10 Example of modular charging station

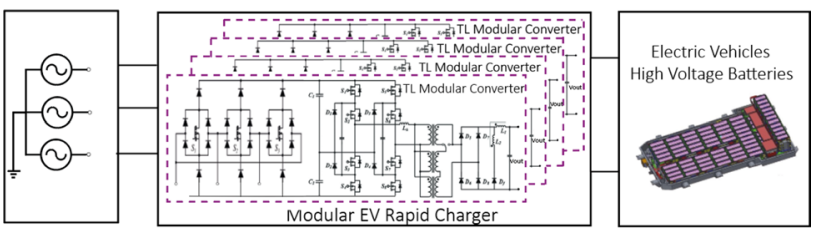

Fig. 11 Block-diagram of the converter proposed in [67]

\section{The design of the cooling system is simplified in the case of modular architecture and the overall system reliability increases.}

In literature different types of modular charger and station have been analyzed [67, 68]. In [67], indeed, a modular converter topology for EV fast charging, shown in Fig. 11, has been proposed. The charger proposed is a $50 \mathrm{~kW}$ rapid charger which consists of four $12.5 \mathrm{~kW}$ modules paralleled connected both at the input and output. Based on the power required by the EV battery a certain number of converters is activated for the charging process. The major strength of this design is the optimization of the overall system efficiency and power density. However, in this case all the modules include the rectification stage resulting in higher costs with respect to the modularization of the dc/ dc part only. Moreover, in this type of design, the split of the power is allowed only for the corresponding charging

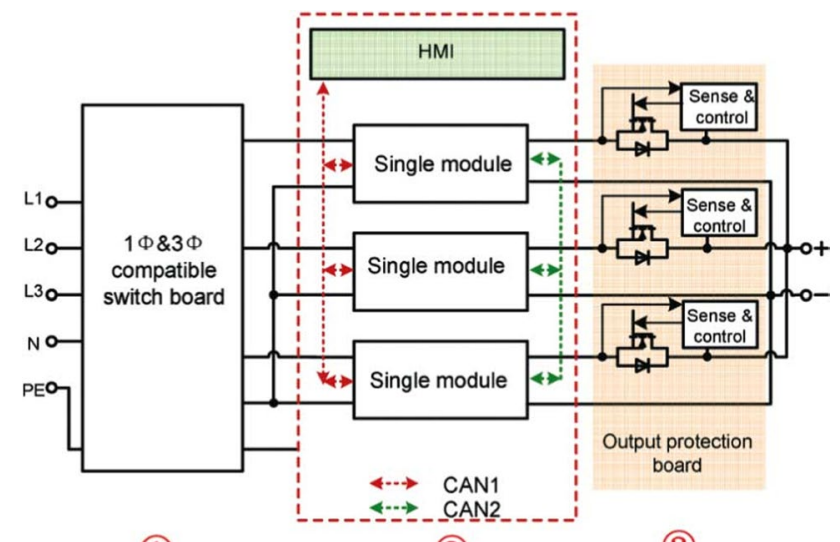

(1)

(2)

(3)

Fig. 12 Modular onboard charger [68]

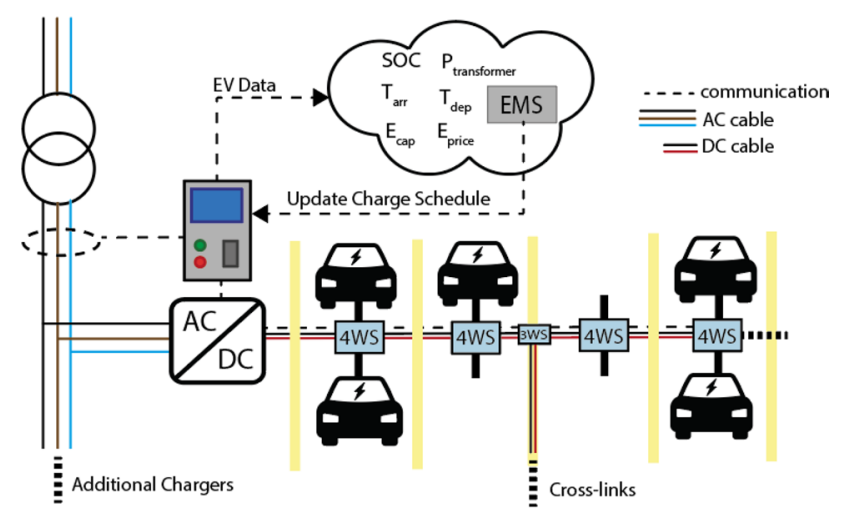

Fig. 13 reconfigurable DC charging network in [69]

port and the modules cannot be shared with the other ports within the charging station.

In Fig. 12 the modular onboard charger presented in [68] is depicted. The logic behind and the design is very similar to the converter proposed in [67], with the difference that this one is installed onboard. Precisely, the onboard charger is composed by three $3.3 \mathrm{~kW}$ modules paralleled connected. Hence the output power of the charger can be enlarged to achieve higher charging rate by paralleling more modules, up to a maximum power of about $10 \mathrm{~kW}$. As the approach described in [67], also this system aims to increase the efficiency at light load operation and to improve charger redundancy.

A reconfigurable, but not modular, charging network is then presented in [69]. As shown in Fig. 13, this charging network bases its operation on controllable switches, similarly to the architectures that will be proposed in this paper. However, the reconfiguration of the network in [69] aims only to achieve the best charging pattern of the connected EVs to minimize the charging cost. In fact, the EVs parked at the station are all connected to a single charger, but they 
are filled one at a time, following the optimized charging schedule dictated by the energy management system (EMS).

Finally, in [70] a fast-charging system based on a modular reconfigurable architecture is presented. In Fig. 14, the block diagram of the switching scheme proposed for the charging station is fully depicted. Each of the $15 \mathrm{~kW}$ modules is composed of a three-phase voltage source rectifier (VSR) and an isolated full-bridge $\mathrm{dc} / \mathrm{dc}$ converter.

The modules are input paralleled connected, instead the outputs can be parallel, or series connected to achieve higher charging current in the first case and to be compatible with EVs with higher battery voltages such as electric buses and trucks in the second configuration case. Particularly, the automatic power distribution unit shown in Fig. 14 allows all these configurations. Nevertheless, this unit allows only the output series/paralleled connection of maximum 2 modules, leading in this way to a maximum charging power of $30 \mathrm{~kW}$.

\subsection{Proposed Architectures}

The paper proposes and analyzes two basic architectures. In both cases, the UFC station is composed of 10 charging ports and $2050 \mathrm{~kW}$ modules. The modules are imagined to be in a common shelter with assumed disposal of 10 per row. In both the architectures the modules located in the lower row are fixedly connected to the corresponding output DC bus bar which in turn is connected to a single charging port. Therefore, these modules are dedicated only to the charging of the vehicle connected to that corresponding charging column. Instead, the modules positioned in the upper line are shared according to the possibilities allowed by the commutators.

The first architecture analyzed (1ST), whose part of the main scheme is reported in Fig. 15a, presents 20 commutators (S1-S20), two for each module placed in the upper row. Figure 15b, instead, highlights the out modules connections

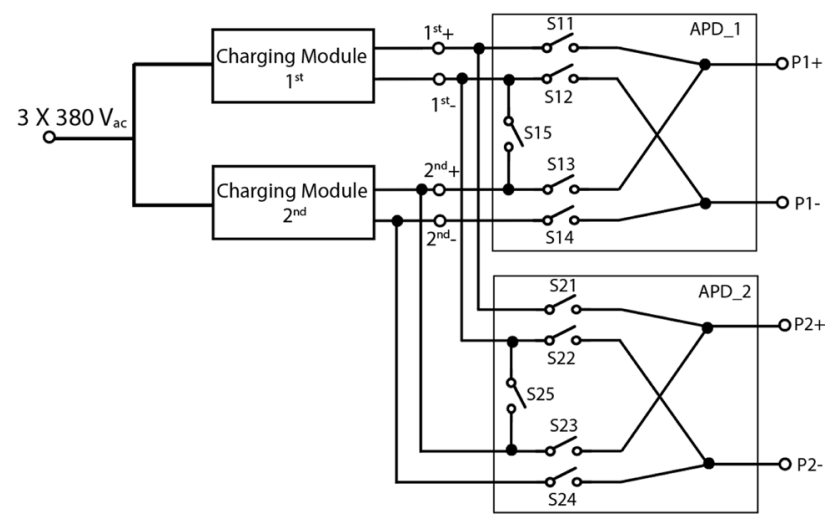

Fig. 14 Switching scheme block diagram used in [70]

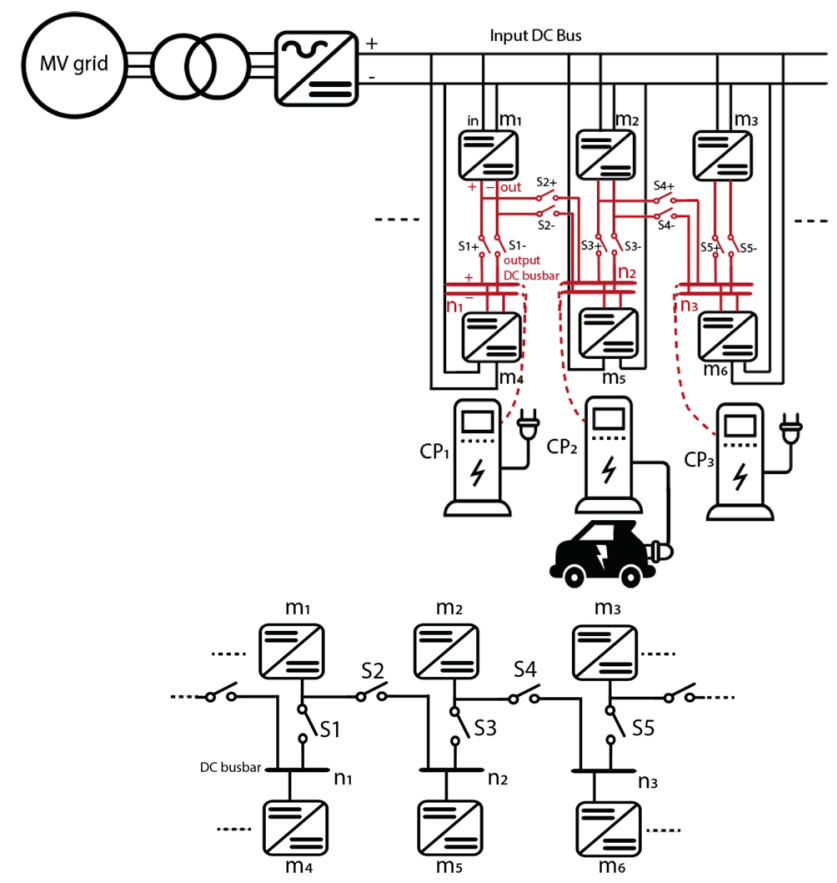

Fig. 15 First proposed modular architecture block diagram: a complete station and $\mathbf{b}$ modules outputs connection

and the switched disposition; for the sake of simplicity, through a single-line diagram.

The decision flowchart of this first proposed configuration is fully depicted in Fig. 16, by taking as example an electric

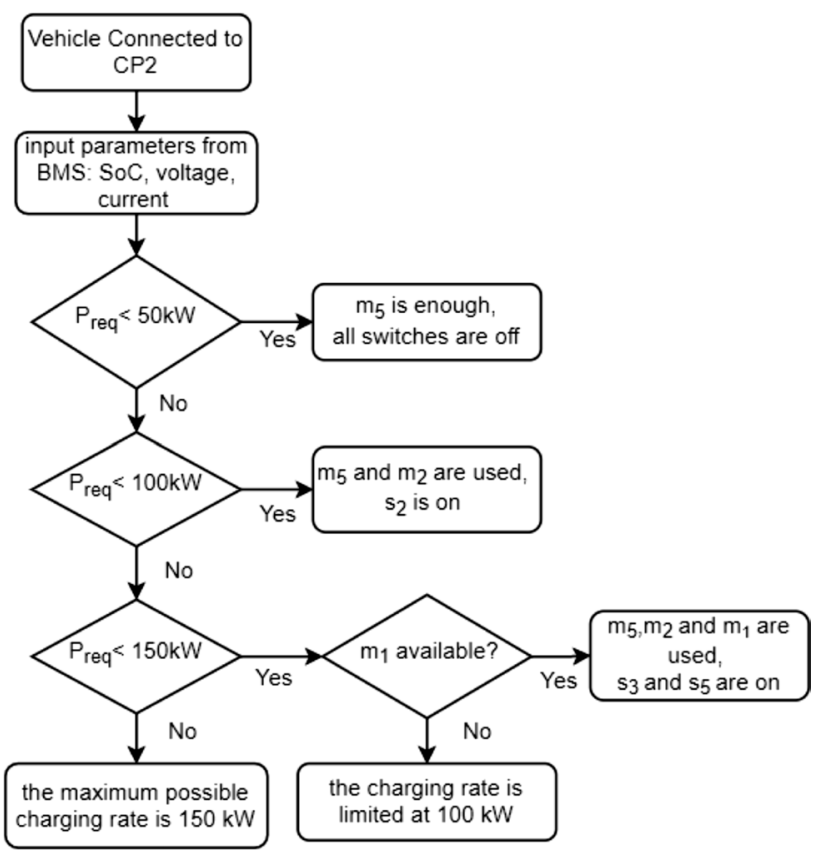

Fig. 16 Decisional flowchart first architecture 
vehicle connected at the charging port 2 as represented in Fig. 15a.

From Fig. 16 It is possible to conclude that, in this first configuration, the modules in the upper line can be shared until reaching a maximum power of $150 \mathrm{~kW}$ for a given charging port. If one upper module is connected to the adjacent port, it means that the vehicle connected to the corresponding column is charging with a speed of maximum of $50 \mathrm{~kW}$, because for the upper module the vehicle connected to the corresponding charging port takes precedence over the other vehicles connected to the adjacent ports. Therefore, a maximum power of $100 \mathrm{~kW}$ is always guaranteed to the vehicles.

The second architecture (2ND) is composed of 20 modules distributed on 10 columns as well. The connection to the electrical grid, which means the input connection to the modules is the same as Fig. 15a. Instead, in Fig. 17 is represented the connection of the output of the DC/DC modules and hence the configuration of the power switches. As Fig. 15 b for the first case, only 6 modules over 20 and 3 charging ports over 10 are illustrated to make the representation clearer. If in the first proposed architecture, the up module can be shared only with the next charging port in terms of the order; instead, in the second architecture (2ND), the up module can be used by both the adjacent charging columns.

Therefore, the decisional flowchart for this configuration, shown in Fig. 18, will have more steps. By taking as example always the connection to the charging port 2 (the dc busbar $n_{2}$ ), the additional step consists in checking the availability of both the up adjacent modules in case the vehicle requires a charging power higher than $100 \mathrm{~kW}$. Moreover, the presence of an extra switch for each charging point, and hence 10 extra switches with respect to the first architecture, for a total of 30 in the UFC station considered, allows the connected vehicles to charge a possible maximum power of $200 \mathrm{~kW}$.

The two architectures are then compared, and the outcomes are reported in Fig. 19.

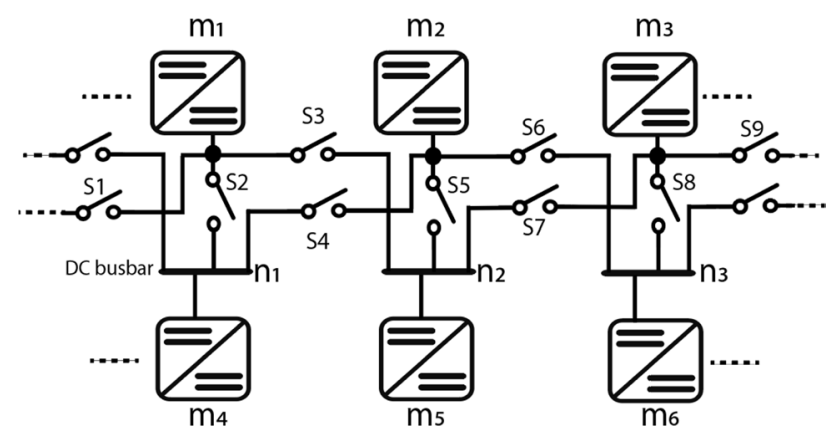

Fig. 17 Second proposed architecture modules output connection block diagram

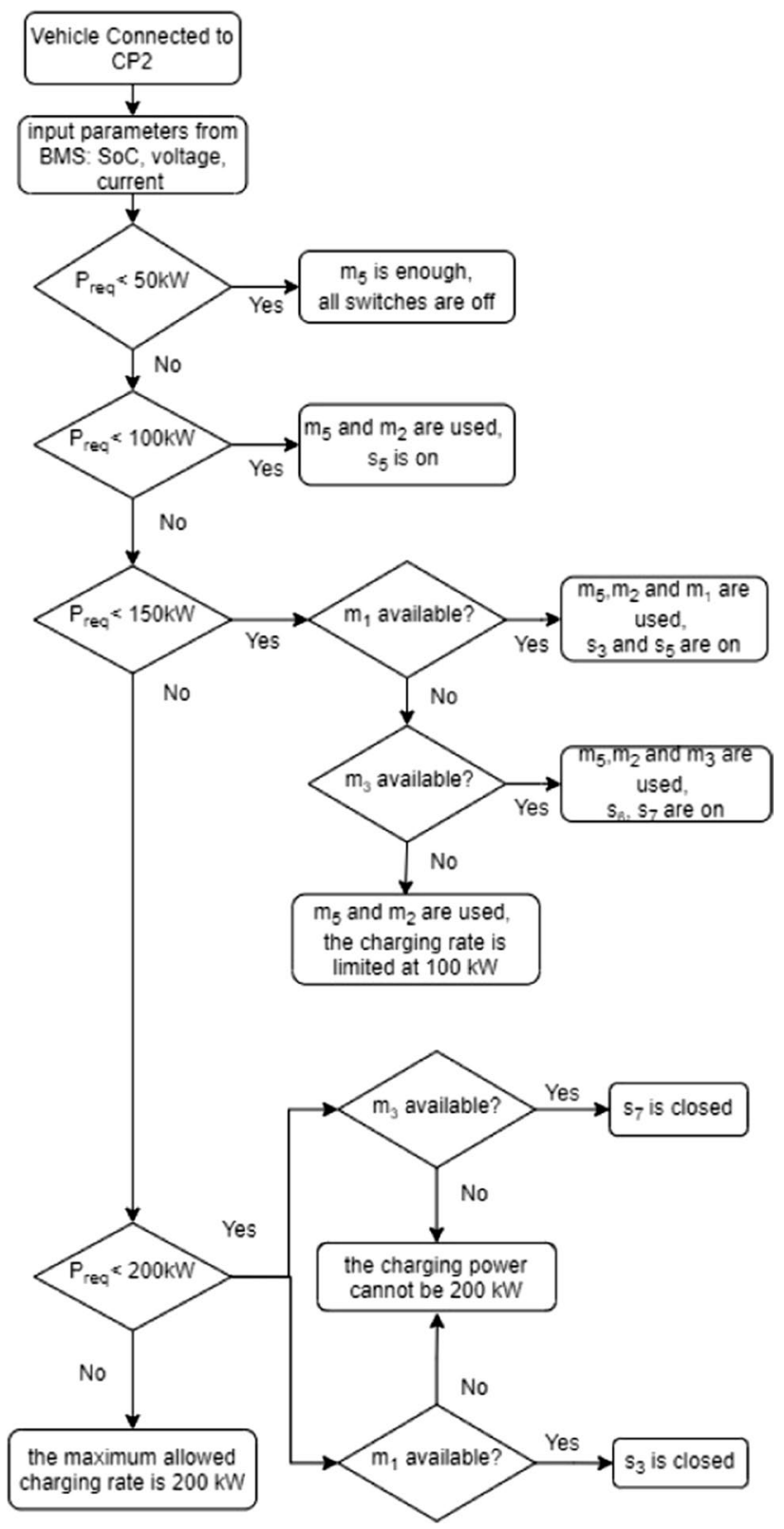

Fig. 18 Decisional flowchart second architecture

The first proposed architecture has only 20 commutators, but it allows a fewer number of configurations resulting in this way in lower costs but also a higher probability for the BEVs to be charged at limited power compared to the allowed one. On the other hand, by increasing the number of commutators, which is increased to 30 in the second proposed architecture, more configurations can be covered, so that the probability of charging EVs with limited power decreases from the $4.1 \%$ of the first architecture to $2.1 \%$. The probability is only for those EVs that have charging profiles that allow power values greater than $50 \mathrm{~kW}$; in fact, the lower module is not shared and hence a charging power 


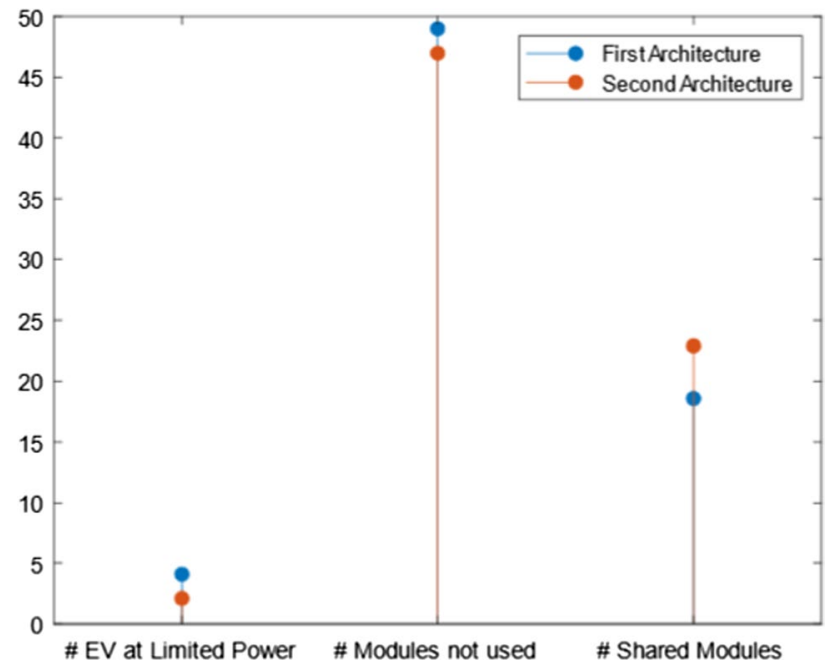

Fig. 19 Comparison proposed modular architectures

of $50 \mathrm{~kW}$ is always guaranteed. It can also be concluded from Fig. 19 that in both architectures the percentage of EVs charging at limited power is less than $5 \%$. In the second architecture, the number of shared modules increases as a result of the higher number of possible configurations, so the probability of having unused modules decreases from 49 to $47 \%$.

\section{Conclusions}

This paper focuses on the design of an ultra-fast charging station for electric vehicles. A probabilistic method for estimating the total absorbed power of the station is presented. The power requirement is calculated taking into account factors such as the simultaneity in the connection and the different charging profiles, and hence characteristics, of the BEVs currently on the market. The result underlines that by dimensioning the overall station with a capacity of about two-thirds of the maximum power, more than $97 \%$ of the possible scenarios can still be covered, thus reducing the impact on the network and the necessary initial investment.

A reduction in the overall power of the UFC station automatically leads to a reduction in the power installed for the DC/DC converters. Therefore, in the second part of this paper, a new modular approach, for reducing the installed power for the chargers, while maintaining the possibility of charging all the electric vehicle models at the maximum speed allowed by their charging curve, is investigated. In the proposed modular approach, the DC/DC stage of the UFC station, containing 10 charging points, consists of 20 identical $50 \mathrm{~kW}$ modules that can be shared between adjacent charging ports depending on the possibilities allowed by the power switches configuration. Two different switches configurations have been proposed. From the results obtained by the comparison of the two, it can be concluded that the second architecture, with more switches, has a better performance in terms of power-sharing; in fact, only $2.1 \%$ of the possibility for an EV to charge with limited power. However, both the proposals allow a greater flexibility in charging vehicles of different sizes, and they also increase the converter's utilization rate and thus the efficiency of the entire charging system.

For the characteristics of the electric cars currently on the market it has been demonstrated that, in both the cases, the probability of charging EVs with limited power is less than 0.05 . However, in the future, the maximum charging power allowed by the EVs is likely to increase; for this reason, the next steps of this research will focus mainly on finding other suitable architectures and on the comparison of the results. Finally, since in this work the size of the modules $(50 \mathrm{~kW})$ has been selected without a proper investigation, then in future steps will also focus on finding the optimal size of the modules which composes the station will be address.

Funding Open access funding provided by Politecnico di Milano within the CRUI-CARE Agreement.

\section{Declarations}

Conflict of interest The authors declare that they have no conflict of interest.

Open Access This article is licensed under a Creative Commons Attribution 4.0 International License, which permits use, sharing, adaptation, distribution and reproduction in any medium or format, as long as you give appropriate credit to the original author(s) and the source, provide a link to the Creative Commons licence, and indicate if changes were made. The images or other third party material in this article are included in the article's Creative Commons licence, unless indicated otherwise in a credit line to the material. If material is not included in the article's Creative Commons licence and your intended use is not permitted by statutory regulation or exceeds the permitted use, you will need to obtain permission directly from the copyright holder. To view a copy of this licence, visit http://creativecommons.org/licenses/by/4.0/.

\section{References}

1. Meyer G Electrification of the Transport System, European Commission, 2017. [Online]. Available: https://op.europa.eu/en/publi cation-detail/-/publication/253937e1-fff0-11e7-b8f5-01aa75ed71 a1/language-en/format-PDF [Accessed on: Jan. 7, 2020]

2. McLaren J, Miller J, O’Shaughnessy E, Wood E, Shapiro E (2016) Emissions associated with electric vehicle charging: impact of electricity generation mix, charging infrastructure availability, and vehicle type. National renewable energy laboratory, Technical report. Available online: https://afdc.energy.gov/files/u/publi cation/ev_emissions_impact.pdf

3. Kobayashi S, Plotkin S, Ribeiro S (2009) Energy efficiency technologies for road vehicles. Energ Effi 2(2):125-137 
4. Zuccari1 F, Orecchini F, Santiangeli A, Suppa T, Ortenzi F, Genovese A, Pede G (2019) Well To Wheel analysis and comparison between conventional, hybrid and electric powertrain in real conditions of use. In: AIP conference proceedingshttps://doi.org/10. $1063 / 1.5138891$

5. Raykin L, MacLean HL, Roorda MJ (2012) Implications of driving patterns on well-to-wheel performance of plug-in hybrid electric vehicles. Environ Sci Technol 46(11):6363

6. Faria R, Pedro M, Moura P, Freire F, Delgado J, Almeida T (2013) Impact of electricity mix and use profile in the life cycle assessment of electric vehicles. Renew Sustain Energy Rev 24:271-287

7. Nealer R, Reichmuth D, Anair D (2015) Cleaner cars from cradle to grave, Union of concerned scientists

8. IEA (2020), Global EV Outlook, IEA, Paris, https://www.iea.org/ reports/global-ev-outlook-2020

9. Yilmaz M, Krein PT (2013) Review of Battery Charger Topologies, Charging Power Levels, and Infrastructure for Plug-In Electric and Hybrid Vehicles. IEEE Trans Power Electron 28(5):2151-2169

10. Righolt HC, Rieck FG (2013) Energy chain and efficiency in urban traffic for ICE and EV. In: world electric vehicle symposium and exhibition. (EVS27), pp 1-7

11. Ashkrof P, . de A. Correia GH, . van Arem B (2020) Analysis of the effect of charging needs on battery electric vehicle drivers' route choice behaviour: a case study in the Netherlands. Transp Res Part D: Transp Environ. https://doi.org/10.1016/j.trd.2019. 102206

12. Yilmaz M, Krein PT (2012) Review of charging power levels and infrastructure for plug-in electric and hybrid vehicles.In: IEEE international electric vehicle conference, Greenville, SC, pp 1-8

13. Hosseinpour S, Chen H, Tang H (2015) Barriers to the wide adoption of electric vehicles: A literature review based discussion. In: Portland international conference on management of engineering and technology (PICMET), Portland, OR, pp 2329-2336

14. Neaimeh M, Salisbury SD, Hill GA, Blythe PT, Scoffield DR, Francfort JE (2017) Analysing the usage and evidencing the importance of fast chargers for the adoption of battery electric vehicles. Energy Policy 108:474-486

15. Ashkrof P, de Almeida GH, Arem CB (2020) Analysis of the effect of charging needs on battery electric vehicle drivers' route choice behaviour: a case study in the Netherlands. Transp Res Part D: Transp Environ. https://doi.org/10.1016/j.trd.2019.102206

16. Gjelaj M, Træholt C, Hashemi S, Andersen PB, 2017 Cost-benefit analysis of a novel DC fast-charging station with a local battery storage for EVs. In: 52nd international universities power engineering conference (UPEC), Heraklion, https://doi.org/10.1109/ UPEC.2017.8231973

17. Febriwijaya YH, Purwadi A, Rizqiawan A, Heryana N (2014) A study on the impacts of DC fast charging stations on power distribution system. In: International conference on electrical engineering and computer science (ICEECS), Kuta https://doi. org/10.1109/ICEECS.2014.7045233.

18. Zhu X, Mather B, Mishra P (2020) Grid impact analysis of heavyduty electric vehicle charging stations. In: IEEE power \& energy society innovative smart grid technologies conference (ISGT), Washington, DC, USA, https://doi.org/10.1109/ISGT45199.2020. 9087651

19. Tu H, Feng H, Srdic S, Lukic S (2019) Extreme fast charging of electric vehicles: a technology overview. IEEE Transactions on Transportation Electrification. https://doi.org/10.1109/TTE.2019. 2958709

20. Frieske B, Kloetzke M, Mauser F (2013) Trends in vehicle concept and key technology development for hybrid and battery electric vehicles. In: world electric vehicle symposium and exhibition (EVS27), Barcelona https://doi.org/10.1109/EVS.2013.6914783
21. Sun L, Lubkeman D, Baran M, Levelized (2019) Cost analysis of medium voltage DC fast charging station. IEEE power \& energy society general meeting (PESGM), Atlanta, GA, USA, pp 1-5

22. S. Srdic, X. Liang, C. Zhang, W. Yu and S. Lukic, (2016) A SiCbased high-performance medium-voltage fast charger for plug-in electric vehicles. IEEE Energy conversion congress and exposition (ECCE), Milwaukee, WI https://doi.org/10.1109/ECCE.2016. 7854777.

23. Farkas C, Szúcs G, Prikler L (2013) Grid impacts of twin EV fast charging stations placed alongside a motorway. In: 4th international youth conference on energy (IYCE), Siofok, pp 1-6

24. Yang B, Lee FC, Zhang AJ, Huang G (2002) LLC resonant converter for front end DC/DC conversion. Proc. 17th Annu IEEE Appl Power Electron Conf Expo (APEC) 2:1108-1112

25. Ta LAD, Dao ND, Lee D (2020) High-efficiency hybrid LLC resonant converter for on-board chargers of plug-in electric vehicles. IEEE Trans Power Electron. https://doi.org/10.1109/TPEL.2020. 2968084

26. Iyer VM, Gulur S, Gohil G, Bhattacharya S (2018) Extreme fast charging station architecture for electric vehicles with partial power processing.In: IEEE applied power electronics conference and exposition (APEC) ,San Antonio, TX, pp 659-665

27. Srdic S, Lukic S (2019) Toward extreme fast charging: challenges and opportunities in directly connecting to medium-voltage line. IEEE Electrification Magazine. https://doi.org/10.1109/MELE. 2018.2889547

28. Ronanki D, Kelkar A, Williamson SS (2019) Extreme fast charging technology - prospects to enhance sustainable electric transportation. Energies. https://doi.org/10.3390/en12193721

29. Sbordone D, Bertini I, Di Pietra B, Falvo MC, Genovese A, Martirano L (2015) EV fast charging stations and energy storage technologies: a real implementation in the smart micro grid paradigm. Electric Power Systems Research. https://doi.org/10.1016/j.epsr. 2014.07.033

30. Chon S, Beall J Intelligent battery management and charging for electric vehicles, Texas instruments, Dallas, Texas (US). Available: http://www.ti.com/lit/wp/spry304a/spry304a.pdf Accessed 20 May 2019

31. Chatterjee P Design considerations for fast DC chargers targeting 350kW". Infineon technologies, Warstein, Germany. Available: https://www.infineon.com/dgdl/Infineon-Design_considerations_ DC_chargers-ART-v01_00-EN.pdf?fileId $=5546 \mathrm{~d} 46269 \mathrm{e} 1 \mathrm{c} 01$ 9016a2ab43fb22560 Accessed on 6 May 2019

32. Mauri G, Valsecchi A (2012) Fast charging stations for electric vehicle: The impact on the mv distribution grids of the milan metropolitan area. IEEE International Energy Conference and Exhibition (ENERGYCON). https://doi.org/10.1109/EnergyCon.2012. 6347725

33. Bai S, Yu D, Lukic S (2010) Optimum design of an EV, PHEV charging station with DC bus and storage system. IEEE Energy Conversion Congress and Exposition Atlanta, GA . https://doi.org/ 10.1109/ECCE.2010.5617834

34. Yunus K, De La Parra HZ, Reza M (2011) Distribution grid impact of Plug-In Electric Vehicles charging at fast charging stations using stochastic charging model. In: Proceedings of the 2011 14th European conference on power electronics and applications, Birmingham, pp 1-11

35. García-Triviño P, Torreglosa JP, Fernández-Ramírez LM, Jurado F (2016) Control and operation of power sources in a medium-voltage direct-current microgrid for an electric vehicle fast charging station with a photovoltaic and a battery energy storage system. Energy 115:38-48

36. Krein PT, Fasugba MA (2017) Vehicle-to-grid power system services with electric and plug-in vehicles based on flexibility in unidirectional charging. CES Transactions on Electrical Machines and Systems. https://doi.org/10.23919/TEMS.2017.7911106 
37. Veneri O (2016) Technologies and Applications for Smart Charging of Electric and Plug-in Hybrid Vehicles. Springer International Publishing. https://doi.org/10.1007/978-3-319-43651-7

38. Rivera S, Wu B, Kouro S (2014) Distributed dc bus EV charging station using a single dc-link h-bridge multilevel converter. In: IEEE 23rd international symposium on industrial electronics (ISIE), Istanbul, pp 1496-1501, https://doi.org/10.1109/ISIE.2014. 6864836.

39. Moeini A, Kankanala SH, Kimball JW (2020) DC link voltage balancing of the active front-end for the extreme fast charging stations. IEEE Energy Conversion Congress and Exposition (ECCE). https://doi.org/10.1109/ECCE44975.2020.9236377

40. IEC (2014) 61851-23:2014 Electric vehicle conductive charging system-Part 23: DC electric vehicle charging station pp 1-159

41. Chakraborty S, Vu H-N, Hasan MM, Tran D-D, Baghdadi ME, Hegazy O (2019) DC-DC Converter Topologies for Electric Vehicles, Plug-in Hybrid Electric Vehicles and Fast Charging Stations: State of the Art and Future Trends. Energies 12(8):1569

42. Tan L, Wu B, Rivera S (2015) A bipolar-DC-bus EV fast charging station with intrinsic DC-bus voltages equalization and minimized voltage ripples. In: IECON 2015 - 41st annual conference of the IEEE industrial electronics society, Yokohama, pp 002190 002195 https://doi.org/10.1109/IECON.2015.7392426

43. . Haritha AS, Jithin KJ (2019) An efficient resonant converter based charging scheme for electric vehicle. In: 2019 5th International conference on advanced computing \& communication systems (ICACCS), Coimbatore, India, p 599-603

44. Ta LAD, Dao ND, Lee D (2020) High-efficiency hybrid LLC resonant converter for on-board chargers of plug-in electric vehicles. IEEE Trans Pow Electron. https://doi.org/10.1109/TPEL.2020. 2968084

45. Hassanzadeh N, Yazdani F, Haghbin S, Thiringer T (2017) "Design of a $50 \mathrm{~kW}$ phase-shifted full-bridge converter used for fast charging applications". In: IEEE vehicle power and propulsion conference (VPPC), Belfort, pp 1-5, https://doi.org/10.1109/ VPPC.2017.8330881.

46. Du Y, Lukic S, Jacobson B, Huang A (2011) "Review of high power isolated bi-directional DC-DC converters for PHEV/EV DC charging infrastructure". In: Proc. IEEE energy convers. congr. Expo. (ECCE), pp 553-560

47. Mauri G, Bertini D, Fasciolo E, Fratti S (2013) "The impact of EV's fast charging stations on the MV distribution grids of the Milan metropolitan area". In: 22nd International conference and exhibition on electricity distribution (CIRED 2013), Stockholm, pp 1-3

48. Sun Y, de Jong ECW, Cuk V, Cobben JFG (2018) "Harmonic resonance risk of massive ultra fast charging station grid integration". In: 18th International conference on harmonics and quality of power (ICHQP), Ljubljana, pp 1-6

49. Fastned (2019) Typical fast charge curves per vehicle. Available online: https://fastnedcharging.com/en/

50. Tomaszewska A, Chu Z, Feng X, O'Kane S, Liu X, Chen J, Ji C, Endler E, Li R, Liu L, Li Y, Zheng S, Vetterlein S, Gao M, Jiuyu D, Parkes M, Ouyang M, Marinescu M, Offer G, Billy W (2019) Lithium-ion battery fast charging: a review. eTransportation. https://doi.org/10.1016/j.etran.2019.100011

51. Mao C, R RE, Li J, Du Z, Belharouak I (2018) Identifying the limiting electrode in lithium ion batteries for extreme fast charging. Electrochem Commun. https://doi.org/10.1016/j.elecom.2018.10. 007

52. Yang X, Wang C (2018) Understanding the trilemma of fast charging, energy density and cycle life of lithium-ion batteries. J Pow Sour. https://doi.org/10.1016/j.jpowsour.2018.09.069

53. Mussa AS, Liivat A, Marzano F, Klett M, Philippe B, Tengstedt C, Lindbergh G, Edström K, Lindström RW, Svens P (2019) Fast-charging effects on ageing for energy-optimized automotive
LiNi1/3Mn1/3Co1/3O2/graphite prismatic lithium-ion cells. J Pow Sour. https://doi.org/10.1016/j.jpowsour.2019.02.095

54. Vezzini A (2014) "Lithium-Ion battery management". In: Pistoia G (ed) Lithium-Ion batteries, Amsterdam: Elsevier, ch. 3, pp 345-360 https://doi.org/10.1016/B978-0-444-59513-3.00015-7

55. Abdi H, Mohammadi-ivatloo B, Javadi S, Khodaei AR, Dehnavi E (2017) "Energy Storage Systems". In: Gharehpetian GB, Mohammad Mousavi Agah S (eds) Distributed generation systems, U.K: Butterworth-Heinemann, ch. 7 https://doi.org/10.1016/B978-012-804208-3.00007-8

56. Fast and Ultra-fast Chargers (2019) Battery University. Available: https://batteryuniversity.com/learn/article/ultra_fast_chargers

57. Pea-da B, Dechanupaprittha S (2015) Impact analysis of fast charging to voltage profile in PEA distribution system by Monte Carlo simulation. In: 7th International conference on information technology and electrical engineering (ICITEE), Chiang Mai, pp 204-208 https://doi.org/10.1109/ICITEED.2015.7408942

58. Ma S, Jiang M, Tao P, Song C, Wu J, Wang J, Deng T, Shang W (2018) Temperature effect and thermal impact in lithium-ion batteries: a review. Prog Nat Sci Mater Int. https://doi.org/10.1016/j. pnsc. 2018.11.002

59. Lindgren J, Lund PD (2016) Effect of extreme temperatures on battery charging and performance of electric vehicles. J Pow Sour. https://doi.org/10.1016/j.jpowsour.2016.07.038

60. How temperature affects batteries (2016) Tawaky. http://www. tawaki-battery.com/how-temperature-affects-batteries/

61. Pesaran A, Santhanagopalan S, Kim GH, (2013) Addressing the impact of temperature extremes on large format $\mathrm{Li}$-ion batteries for vehicle applications. In: Proceedings of the 30th international battery seminar, Ft. Lauderdale, Florida

62. Chen W, Ruan X, Yan H, Tse CK (2009) DC/DC conversion systems consisting of multiple converter modules: stability, control, and experimental verifications. IEEE Trans Pow Electron 24(6):1463-1474

63. Juan YL, Chen TR, Chang HM, Wei SE (2017) Design of an input-parallel output-parallel LLC resonant DC-DC converter system for DC microgrids. IOP Conf Ser Earth Environ Sci. https:// doi.org/10.1088/1755-1315/94/1/012101

64. Suarez C, Martinez W (2019) "Fast and ultra-fast charging for battery electric vehicles-A review. "IEEE energy conversion congress and exposition (ECCE), Baltimore, MD, USA, pp 569-575

65. Linse C, Kuhn R (2015) Design of high-voltage battery packs for electric vehicles. In: advances in battery technologies for electric vehicles, Woodhead Publishing, ch. 10, pp 245-263 https://doi. org/10.1016/B978-1-78242-377-5.00010-8

66. Suryadevara R, Li T, Modepalli K, Parsa L (2019) IPOP-connected FB-ZCS DC-DC converter modules for renewable energy integration with medium-voltage DC grids. IEEE Trans Ind Appl 55(5):5128-5140

67. Kim JM, Lee J, Eom TH, Ryu K, Shin MH, Won CY. (2019) Modular EV rapid charger design and control method. In: 22nd International conference on electrical machines and systems (ICEMS), Harbin, China, pp 1-5 https://doi.org/10.1109/ICEMS. 2019.8922320

68. Lin Z, Luo X, Jiang Y, Fan L, Wu Y, Zhang Y. (2019) A novel maximum efficiency point tracking technique for modular paralleled electric vehicle charging system. IEEE energy conversion congress and exposition (ECCE), Baltimore, MD, USA, pp 12151222, https://doi.org/10.1109/ECCE.2019.8912168.

69. Mokgonyana L, Smith K, Galloway S (2019) Reconfigurable low voltage direct current charging networks for plug-in electric vehicles. IEEE Trans Smart Grid 10(5):5458-5467. https://doi.org/10. 1109/TSG.2018.2883518

70. Yuan Z, Xu H, Chao Y, Zhang Z (2017) A novel fast charging system for electrical vehicles based on input-parallel output-parallel and output-series.In: 2017 IEEE transportation electrification 
conference and expo, Asia-Pacific (ITEC Asia-Pacific), Harbin, pp 1-6 https://doi.org/10.1109/ITEC-AP.2017.8080843.

Publisher's Note Springer Nature remains neutral with regard to jurisdictional claims in published maps and institutional affiliations.

Carola Leone received the M.S. degree in electrical engineering from the Politecnico di Milano, Milan, Italy, in 2017. She is currently pursuing the Ph.D. degree with the Department of Energy, Politecnico di Milano. Her main field of interest is charging infrastructure for electric vehicle.
Michela Longo received the M.Sc. degree in information engineering and the Ph.D. degree in mechatronics, information, innovative technologies and mathematical methods from the University of Bergamo, Bergamo, Italy, in 2009 and 2013, respectively. She is currently an Assistant Professor at the Department of Energy, Politecnico di Milano, Milano, Italy. Her area of research includes electric power systems, electric traction, and mechatronics. Dr. Longo is a member of the Italian Group of Engineering about Railways (CIFI) and the Italian Electric Association (AEIT). 